Research Article

\title{
Seismic Response Reduction of Megaframe with Vibration Control Substructure
}

\author{
Jun-Qi Huang, ${ }^{1,2}$ Xun Chong, ${ }^{1}$ Qing Jiang $\mathbb{D}^{1,3}$ Xian-Guo Ye, ${ }^{1}$ and Han-Qin Wang ${ }^{1}$ \\ ${ }^{1}$ School of Civil and Hydraulic Engineering, Hefei University of Technology, Hefei 230009, China \\ ${ }^{2}$ Department of Civil and Environmental Engineering, The Hong Kong Polytechnic University, Hung Hom, Kowloon, Hong Kong \\ ${ }^{3}$ State Key Laboratory of Subtropical Building Science, South China University of Technology, Guangzhou 510640, China
}

Correspondence should be addressed to Qing Jiang; jiangq@hfut.edu.cn

Received 14 February 2018; Revised 7 May 2018; Accepted 16 July 2018; Published 26 August 2018

Academic Editor: Evgeny Petrov

Copyright ( 2018 Jun-Qi Huang et al. This is an open access article distributed under the Creative Commons Attribution License, which permits unrestricted use, distribution, and reproduction in any medium, provided the original work is properly cited.

\begin{abstract}
Megaframe with vibration control substructure (MFVCS) is a tuned mass damper system, which converts the substructures into the tuned mass. In this study, a kind of MFVCS using both lead-rubber bearings and viscous dampers to connect the vibration control substructure with the megaframe was proposed. Then, based on a validated finite element model, a parametric analysis was conducted to study the effect of two parameters, the tuning frequency (i.e., the frequency of the substructure) and the damping provided by the lead-rubber bearings and viscous dampers on the seismic response reduction of the MFVCS under both frequent and rare earthquakes (i.e., probability of exceedance of $63 \%$ and $2 \%$ in 50 years, resp.). Furthermore, the optimized values of these two parameters were achieved. The results indicated that (1) the proposed MFVCS could provide a considerable seismic response reduction under frequent earthquake and showed a strong robustness; (2) the optimized values of the frequency ratio (ratio of tuning frequency to the megaframe's natural frequency) and damping scale factor (ratio between the investigated damping and a standard value) were 0.96 and 1.0, respectively; and (3) the seismic response reduction of the MFVCS under rare earthquake was lower than that under frequent earthquake.
\end{abstract}

\section{Introduction}

A megaframe structural system is composed of an exterior megaframe, which resists both gravity and lateral loads, and a number of interior substructures, which are located between the two megabeams and designed for their own gravity loads only. Traditionally, the megacolumns are constructed with shear walls and the megabeams are constructed with transfer floor trusses. The megaframe has many structural and constructional benefits, such as high lateral stiffness, flexible design, and short construction period. According to Ali and Moon [1], it has the potential to reach a height of more than 100 stories. For this type of tall building, the lateral load, especially the seismic load, is the governing factor during design. Herein, the authors of this study conducted a shaking table test on a traditional reinforced concrete megaframe structure and summarized that a slight to medium damage (characterized by the cracking on megacolumns and megabeams) could be observed when peak ground acceleration
(PGA) of the input ground motion reached 880 gal (the corresponding PGA of the prototype structure was 220 gal) [2]. Fan et al. [3] conducted a finite element (FE) analysis on the seismic performance of a megaframe structure with steelbrace core (Taipei 101 building) and concluded that the structure could meet the design requirement even if $\mathrm{PGA}=390$ gal. Lu et al. [4] conducted a FE analysis on the collapse process of a megaframe structure with core tube (Shanghai Tower) under very rare earthquake and found that collapse would occur when PGA $=1960$ gal. Because these studies have already confirmed the high seismic collapse resistance of a megaframe, in the current stage, the effective reduction of its seismic response tends to be an increasingly important issue, which aims to improve human comfort (under frequent earthquake) and structure damage reduction (under rare earthquake).

A tuned mass damper (TMD) is a typical vibration control device, which was proposed by Frahm [5] in 1909 and implemented by Ormondroyd and Den Hartog [6]. 
Its effectiveness in vibration response control has been studied for more than a century [7-9]. The conventional TMD adopts a small additional mass, and it is always installed at the top of the building to achieve a better vibration control [10], such as in the Taipei 101 building. According to previous studies, the conventional TMD system can provide higher reduction in wind response than in seismic response [11-13]. Although increasing the mass ratio of a TMD could enhance its performance regarding seismic response reduction $[2,13]$, this is impossible to achieve in practical engineering because the additional mass in conventional TMD systems has already been a critical safety concern. Previously, the authors of the present study conducted a shaking table test and FE analysis to evaluate the seismic response reduction of a traditional reinforced concrete megaframe with a conventional TMD. The results indicated that the seismic response reduction of the megaframe could be enhanced, whereas the additional mass weight should be even $2 \%$ of the structure weight [2].

In order to solve the problem, researchers tried to convert the existing mass of the structure (i.e., the substructures of megaframe) into the tuned mass [14]. Hence, the whole structure becomes a TMD system with a large mass ratio and no additional mass is required, and the megaframe with vibration control substructure (MFVCS) was thus proposed [15]. During the past several decades, a series of studies on the vibration control of MFVCS were conducted. Feng and Mita [15], Feng and Chai [16], Chai and Feng [17, 18], Lan et al. [19], Zhang et al. [20, 21], Li et al. [22], Lian et al. [23], and Li et al. [24] developed a theoretical or simplified FE model to study the performance of the MFVCS under wind or seismic loads. Lan et al. [25] conducted a shaking table test to compare the dynamic behavior between the traditional megaframe and MFVCS under seismic load. Li et al. [26] conducted a shaking table test to evaluate the dynamic behavior of three steel MFVCSs. Those studies validated the high performance (in terms of both seismic and wind response reduction) of the MFVCS and indicated a practical way to construct an optimal MFVCS, which uses lead-rubber bearings to connect the bottom of the substructure columns with the megabeam below.

Although considerable work has been done in this area, some key problems still exist. (1) The damping provided by the bearings would be limited, which might restrict the seismic response reduction effect. (2) The tuning frequency (i.e., the frequency of the substructure) and the damping provided by the lead-rubber bearings are two key parameters that will influence the seismic response reduction of the MFVCS and determine the parameter selection of the bearings during the design phase. However, there is a lack of information on the optimization of these parameters. (3) The robustness of the seismic response reduction remains unknown when ground motion and the two key parameters are considered as the uncertainties, although the robustness study on the seismic response reduction is necessary for a TMD system [27].

In this study, a new kind of MFVCS with a single vibration control substructure was proposed. In this structure, the top substructure was converted into a tuned mass by using not only lead-rubber bearings to connect the bottom of the substructure columns with the megabeams below but also viscous dampers to connect the top substructure corners with the nearby megacolumns. A FE model was developed to simulate the dynamic behavior of the megaframe structure under seismic load, and its accuracy was calibrated by a shaking table test conducted by the authors. Based on the validated FE model, a parametric analysis on 814 working conditions (36 MFVCS and 1 traditional megaframe counterpart under 22 ground motions) was conducted to study the effect of the two parameters (i.e., the tuning frequency and damping provided by the lead-rubber bearings and viscous dampers) on the seismic response reduction under frequent earthquake (i.e., probability of exceedance of $63 \%$ in 50 years). The root-mean-square ratio (RMSR) of the top displacement was introduced for evaluating the performance of seismic response reduction. Furthermore, the optimized two key parameters were adopted for investigating the seismic response reduction under rare earthquake (i.e., probability of exceedance of $2 \%$ in 50 years). The main purpose of this study is to (1) evaluate the effectiveness of the MFVCS using both lead-rubber bearings and viscous dampers as connecting devices; (2) provide the optimal values of the key parameters that influence the seismic response reduction for design use, considering different earthquake fortification levels; (3) estimate the robustness of the seismic response reduction when the ground motion and two key parameters were considered as the uncertainties.

\section{FE Modelling}

A FE model of a megaframe structure was developed using the general FE program ABAQUS. Details of the material property, element type, and analysis method are as follows.

2.1. Materials Property of Concrete and Steel. A concrete damage plasticity model was used for the concrete behavior of the megacolumn. In this model, the linear and nonlinear behavior of concrete should be defined first. For linear behavior, Poisson's ratio was assumed to be 0.2 . The elastic modulus was calculated according to the following equation [28]:

$$
E_{\mathrm{c}}=4700 \sqrt{f_{\mathrm{c}}}
$$

where $f_{\mathrm{c}}$ is the concrete axial compressive strength (unit: $\mathrm{MPa}$ ) and it was obtained as 0.76 times as much as the concrete cube strength.

For the nonlinear behavior of concrete, the material dilation angle, eccentricity parameter, shape factor for yield surface, and ratio of initial equibiaxial compressive yield stress to initial uniaxial compressive yield stress were taken as $30^{\circ}, 0.1,0.667$, and 1.16 , respectively. The uniaxial stressstrain $(\sigma-\varepsilon)$ relationship is shown in Figure 1(a). Herein, the compressive curve started with a Hognestad parabolic curve until the compressive strength was reached, and it was 


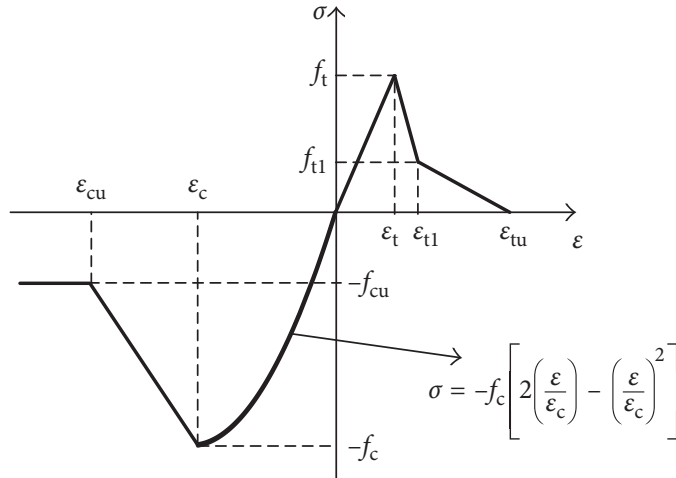

(a)

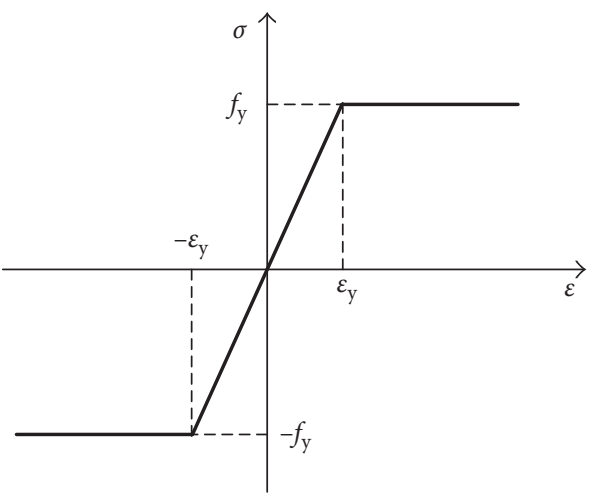

(b)

FIgURE 1: Uniaxial stress-strain relationship of (a) the concrete and (b) steel in this study.

followed by a linear decrease stage. The values of $f_{\mathrm{cu}}, \varepsilon_{\mathrm{c}}$, and $\varepsilon_{\mathrm{cu}}$ in Figure 1(a) were assumed to be $0.2 f_{\mathrm{c}},-0.002$, and -0.004 , respectively. The tensile curve started with a linear curve until the tensile strength was reached, and it was followed by a softening stage. The tensile strength of concrete was $0.62 \sqrt{f_{\mathrm{c}}}$ [28]. $f_{\mathrm{t} 1}, \varepsilon_{\mathrm{t} 1}$, and $\varepsilon_{\mathrm{tu}}$ in Figure $1(\mathrm{a})$ were assumed to be $0.5 f_{\mathrm{t}}, 0.002$, and 0.006 , respectively, for quick convergence.

It should be noted that for beams, braces, and columns, the property of concrete was simplified in such a way that only the uniaxial compressive behavior in Figure 1(a) was considered. This material property model was implemented into the FE model through a user subroutine (UMAT) because a lack of the concrete constitutive model was defined for the fiber element within the framework of the software package.

In this study, the steel rebar and steel tube adopted the same material model with different yield strength values. For linear behavior, the elastic modulus and Poisson's ratio were $200 \mathrm{GPa}$ and 0.2 , respectively. The nonlinear uniaxial behavior of the steel is shown in Figure 1(b), which contained an initial linear increase stage and a perfectly plastic stage afterwards. The $f_{\mathrm{y}}$ and $\varepsilon_{\mathrm{y}}$ in the figure were the yield strength and the corresponding strain, respectively.

2.2. Element Type and Analysis Method. The floor slab and shear wall of the megacolumn were modelled using a 4-node shell element (S4R). All beams, columns, and braces were modelled using a fiber beam element (B31). The "* rebar" command was used for inserting the steel rebar fibers into the reinforced concrete members. Rayleigh damping was adopted for the whole structure.

In MFVCS, the viscous damper was modelled by using the dashpot element. For the lead-rubber bearing, as indicated by the Eurocode 8 [29], its mechanical behavior could be replaced by the equivalent linear model, which was characterized by effective stiffness and viscous damping. This model could help us to reduce the computation time and achieve an easy convergence. Therefore, in the present study, the equivalent linear model was adopted for the behavior of lead-rubber bearing, and it was modelled by using a linear spring combined with a dashpot element. It should be noted that such linearization was considered very approximate for the nonlinear lead-rubber bearing used in practice [30]. Nevertheless, one main purpose of this study was to achieve the optimized values of the tuning frequency and viscous damping to guide the design of the MFVCS. The effective stiffness and damping value of the equivalent linear model could be calculated from these two parameters directly. Therefore, it was logical to emulate the bearings with this kind of model. Besides, during the design of the MFVCS, if the parameters of the lead-rubber bearings can be reasonably chosen, the practical effective stiffness and damping can be close to the optimized values. In this case, the results from the approximate method would be reliable.

The implicit method was adopted for the dynamic analysis. The ground motion acceleration was input as a tabular form through the command "*AMPLITUDE" and added to the base nodes of the model. The translation degrees of freedom perpendicular to the loading direction were restrained. It should be noted that according to the Chinese design code (GB50011-2010) [31], the design of a tall building can be divided into two stages. The first stage is the elastic analysis of the structure model under frequent earthquake to ensure that the lateral displacement could meet the requirement for human comfort. The second stage is the elastoplastic analysis of the structure model under rare earthquake, and the objective is to ensure that no serious damage occurs in the structure. Similarly, in this study, only the linear behavior of the material was considered in the FE analysis under frequent earthquake. The nonlinear behavior of the material was only considered in the analysis under rare earthquake.

\section{Validation of the FE Model}

A shaking table test conducted on a traditional megaframe structure [2] was used to validate the FE model. Details of the prototype building and shaking table test, and the comparison between test and analysis, are described in this section. 


\subsection{Introduction of the Shaking Table Test for the Megaframe}

3.1.1. Prototype Building. The prototype building was a 55story reinforced concrete megaframe structure, which was designed according to the Chinese design code (GB500112010 [31] and JGJ3-2002 [32]). This megaframe was assumed to be located in a region with 7-degree seismic design intensity. The corresponding peak ground acceleration (PGA) value of the design earthquake (i.e., probability of exceedance of $10 \%$ in 50 years) was 100 gal. The site condition was site class II. The design wind load was $0.35 \mathrm{kN} / \mathrm{m}^{2}$. The building had a geometrical size of $39 \mathrm{~m} \times 36 \mathrm{~m} \times 201 \mathrm{~m}$ (length $\times$ width $\times$ height). Four rectangular megacolumns were located at the corners of the structure and each of them had a size of $7.8 \mathrm{~m} \times 7.2 \mathrm{~m}$. The megacolumn was made of a tubular shear wall with four concrete-filled steel tube(CFST-) embedded columns in each corner. The megabeams, which were located at the 11th, 22nd, 33rd, 44th, and 55th floor of the building, were constructed with spatial trusses. Five identical substructures inside the main structure were the moment-resisting frames. The story heights of the megabeam and substructure were $4.2 \mathrm{~m}$ and $3.6 \mathrm{~m}$, respectively. Details of the megaframe and megabeam can be seen in Figure 2.

The shear wall of the megacolumn was constructed with different thickness and concrete strength along the height of the building. For the 1st-13th, 14th-24th, 25th-35th, and 36th-55th floors, the shear wall thickness was $700 \mathrm{~mm}$, $600 \mathrm{~mm}, 500 \mathrm{~mm}$, and $400 \mathrm{~mm}$, respectively. For the 1st16th, 17th-27th, and 28th-55th floors, the designed concrete cube strength of the shear wall was $60 \mathrm{MPa}, 50 \mathrm{MPa}$, and $40 \mathrm{MPa}$, respectively. The floor thickness was $200 \mathrm{~mm}$ and $100 \mathrm{~mm}$ for the megabeam and substructure, respectively. The beams in the substructure were steel rebar reinforced concrete beams, which had a section of $300 \mathrm{~mm} \times 650 \mathrm{~mm}$, and the beams in the megabeam were steel reinforced concrete (SRC) beams with the same geometrical size.

3.1.2. Shaking Table Test. For the shaking table test, a 1/25 scale model was constructed, which included the megaframe, additional mass, and basement. Microconcrete, copper, and steel wires were adopted for representing the concrete, steel tube, and steel rebar, respectively. The interaction between the foundation and soil was eliminated by fixing the model on the shaking table. Details of the test model are shown in Figure 3(a).

The megaframe model was tested under different load cases, and white noise was introduced for measuring the natural frequency before and after each load case. These load cases were defined according to different combinations of ground motion (Imperial Valley ground motion (El-Centro station, NS component, 1940), Wenchuan ground motion (MZQ station, EW component, 2008), Chi-Chi ground motion (TCU052 station, EW component, 1999), and an artificial ground motion), loading direction $(X, X+Y$, and $X+Y+Z$ in Figure 2), and PGA (140 gal, $280 \mathrm{gal}, 400 \mathrm{gal}$, $880 \mathrm{gal}$, and $1200 \mathrm{gal})$. The ratio of PGA along the $X, Y$, and $Z$ directions was $1: 0.85: 0.65$ for a multidirectional input. It should be noted that the PGA of 140 gal and 880 gal in the shaking table test represented the frequent and rare earthquakes (35 gal and 220 gal according to [31]) in the prototype building, respectively.

3.2. Analysis Results. The FE model of the tested megaframe model is shown in Figure 3(b). The comparison of natural frequency in the $X$ direction (Figure 2) between the test and FE analysis results is shown in Table 1 . The mode shape of the corresponding natural frequency is shown in Figure 4. From Table 1, the error between test and analysis results was within $10 \%$, which indicated that the FE model could give a reasonable prediction of the natural frequency of a megaframe.

The test results of the megaframe model under Imperial Valley ground motion ( $X$ direction) with $\mathrm{PGA}=140 \mathrm{gal}$ and $\mathrm{PGA}=880$ gal were used for the validation of the FE model under the frequent and rare earthquakes, respectively. Figure 5 presents the comparison of the time-history response of the top displacement between the test and analysis results. It could be seen that the FE model could give a reasonable prediction on the time-history response of the megaframe, including the shape of the curve and maximum lateral displacement.

Summarizing, the comparison between test and analysis results indicated that the FE model could be used to simulate the dynamic behavior of a megaframe structure under frequent and rare earthquakes.

\section{Parametric Analysis Based on the Validated FE Model}

4.1. Description of the Parametric Analysis. Based on the validated FE model, parametric analysis was conducted to study the seismic response reduction of the proposed MFVCS. As mentioned above, this unconventional tuned mass damper (TMD) system was formed by converting the top substructure of the traditional megaframe (Figure 2) into the tuned mass. Details of the MFVCS FE model are shown in Figure 6. The investigated parameters were the tuning frequency and damping provided by the lead-rubber bearings and viscous dampers, which were the key factors that influenced the seismic response reduction of the MFVCS. Different tuning frequencies were achieved by changing the stiffness of the leadrubber bearing (i.e., the spring element in the FE model). The frequency ratio $(f)$ was introduced for representing the levels of the tuning frequency. The equation for calculating $f$ is as follows:

$$
f=\frac{f_{\text {sub }}}{f_{\text {mega }}},
$$

where $f_{\text {sub }}$ is the tuning frequency (i.e., the frequency of the top substructure) and $f_{\text {mega }}$ is the first mode natural frequency of the megaframe without the top substructure. 


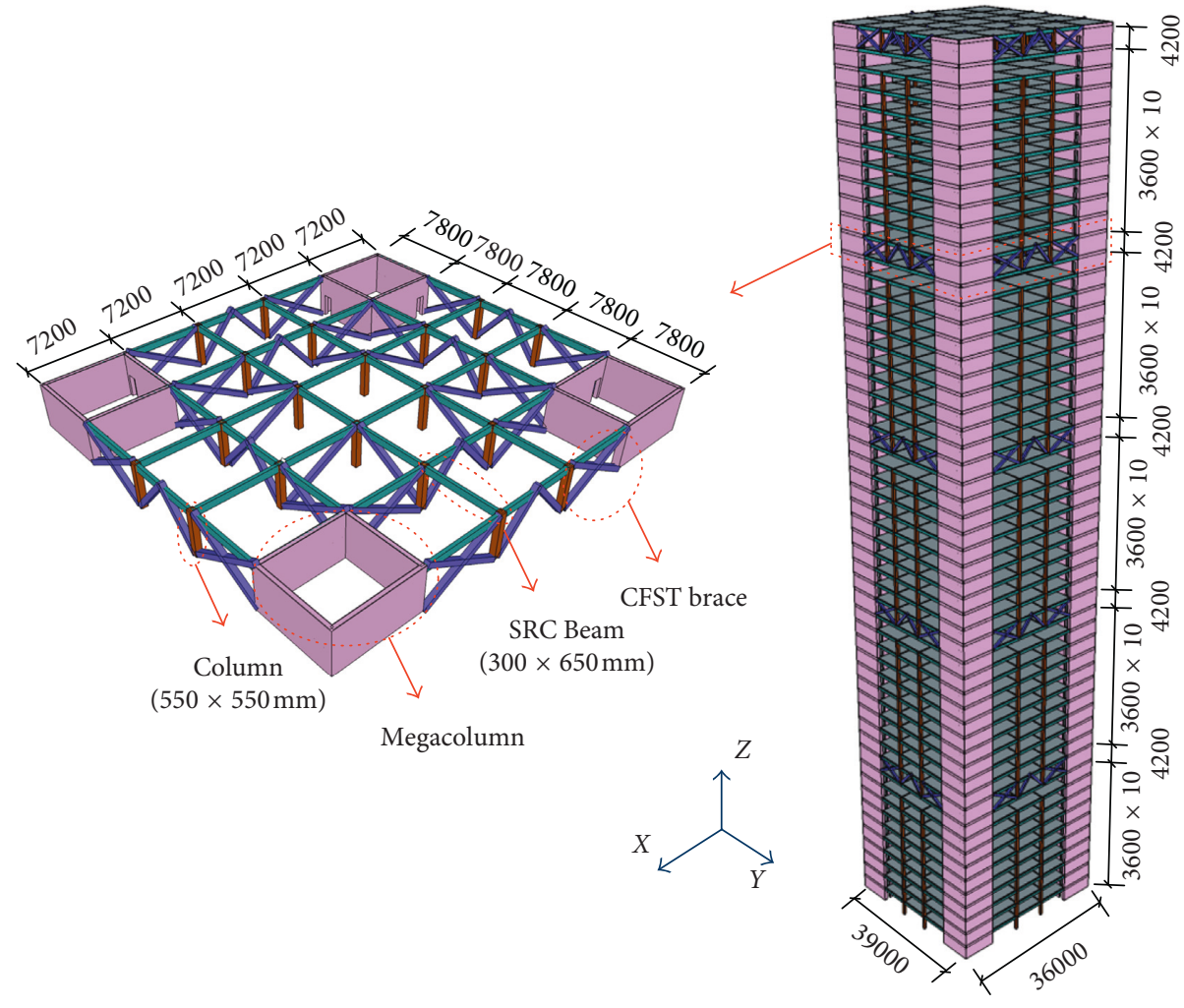

FIGURe 2: Prototype of the megaframe building and details of the megabeam (unit: mm).

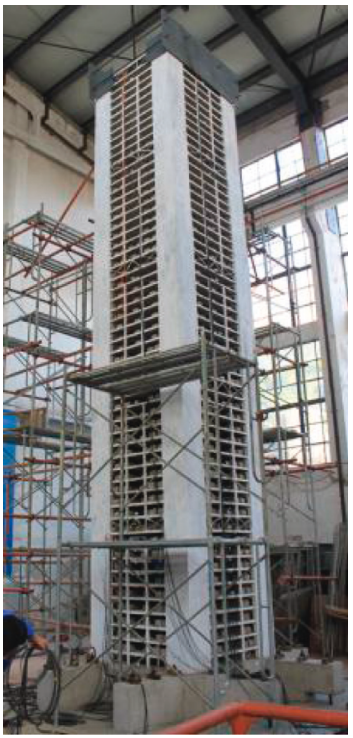

(a)

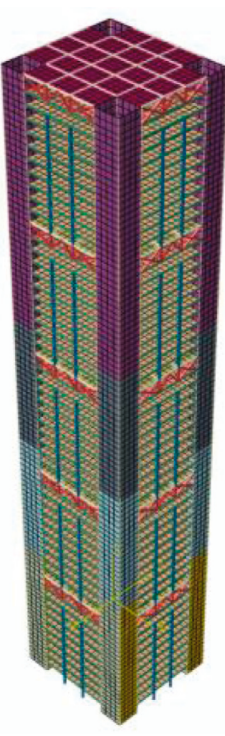

(b)
FIgUre 3: (a) Shaking table test model and (b) FE model of the shaking table test model.

Different values of the investigated damping were achieved by changing the coefficient of the dashpot element in the FE model. In this study, the damping value provided by the lead-rubber bearing and the viscous damper were assumed to be equal, and the damping value of a typical
TABle 1: Comparison of natural frequency in the $X$ direction between test and analysis results.

\begin{tabular}{lccc}
\hline \multirow{2}{*}{ Mode order } & \multicolumn{2}{c}{$\begin{array}{c}\text { Natural frequency in the } X \\
\text { direction }(\mathrm{Hz})\end{array}$} & Error (\%) \\
& Test result & Analysis result & \\
\hline First mode & 1.961 & 1.984 & 1.190 \\
Second mode & 6.329 & 6.897 & 8.966 \\
Third mode & 13.514 & 14.493 & 7.246 \\
Fourth mode & 22.222 & 24.390 & 9.756 \\
\hline
\end{tabular}

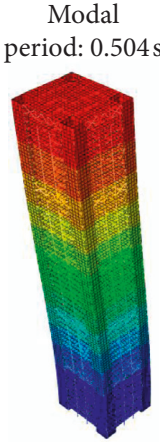

(a)

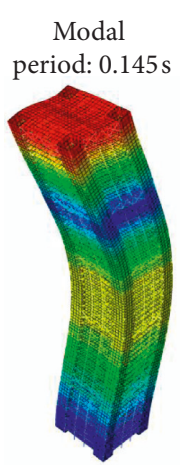

(b)

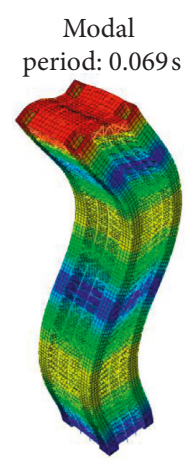

(c)

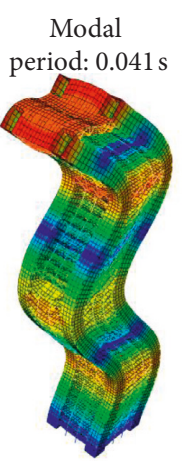

(d)
FIGURE 4: Mode shape and modal periods from the FE analysis: (a) first mode, (b) second mode, (c) third mode, and (d) fourth mode. 


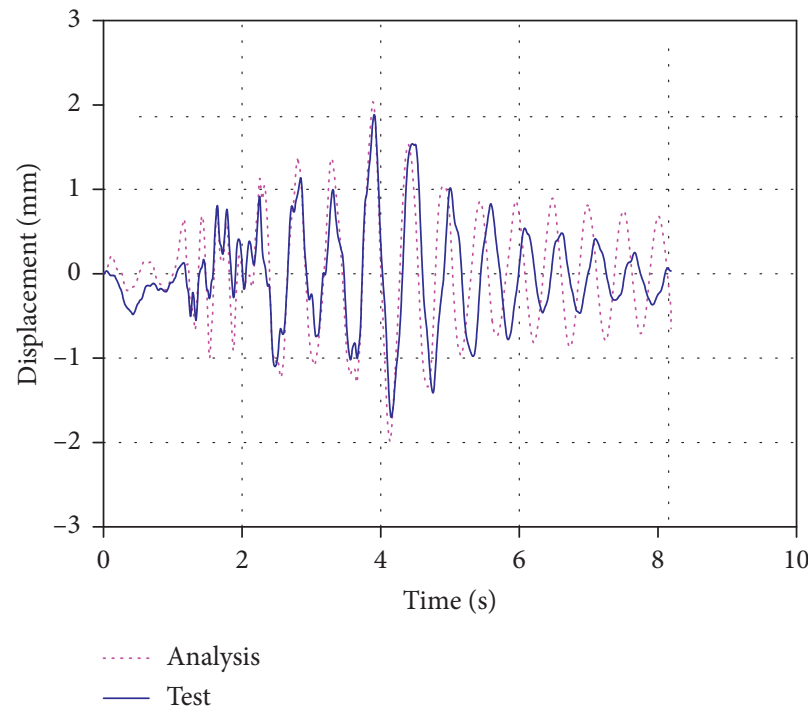

(a)

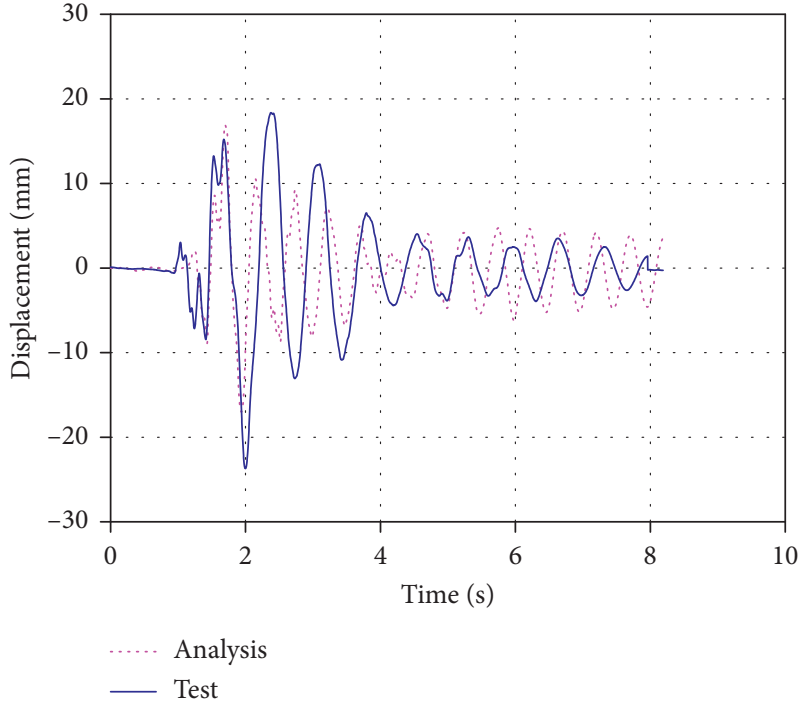

(b)

Figure 5: Comparison on the time-history response of the top displacement between test and FE analysis results. (a) Frequent earthquake $(\mathrm{PGA}=140$ gal). (b) Rare earthquake $(\mathrm{PGA}=880 \mathrm{gal})$.

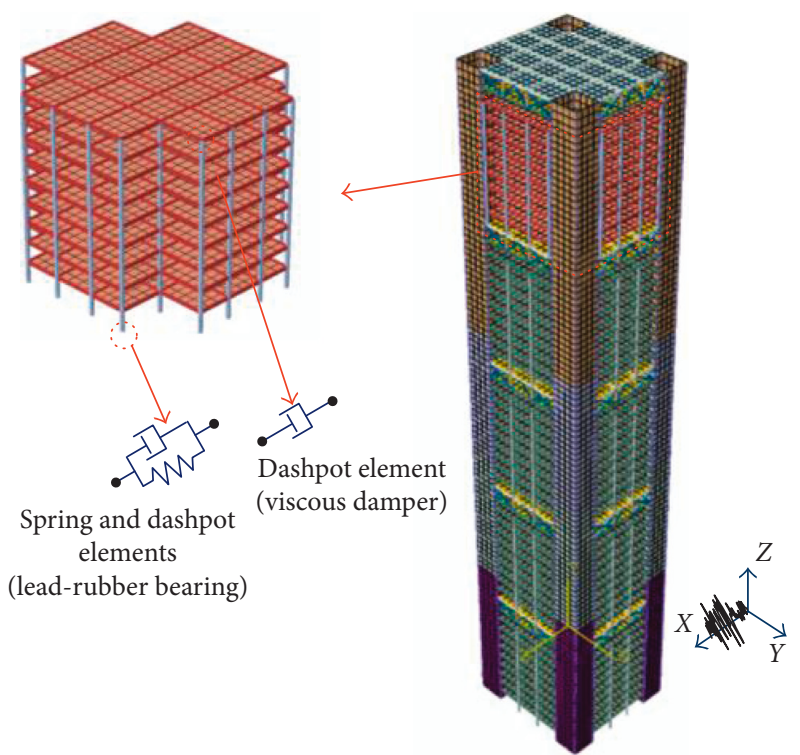

FIGURE 6: FE model of MFVCS.

commercial lead-rubber bearing in China $(187336 \mathrm{~N} \cdot \mathrm{s} / \mathrm{m})$ [33] was adopted as the standard damping value. Thus, the damping scale factor $(\alpha)$ was introduced for representing different levels of the investigated damping value. The calculation of $\alpha$ is shown in the following equation:

$$
\alpha=\frac{c}{187336 \mathrm{~N} \cdot \mathrm{s} / \mathrm{m}}
$$

where $c$ is the damping value provided by the lead-rubber bearings or the viscous dampers.

The whole parametric analysis could be divided into two stages. In the first stage, the effect of $f$ and $\alpha$ on the seismic response reduction of the MFVCS under frequent earthquake ( $P G A=35$ gal) was studied. A total of 36 parameter sets were formed by considering six levels for both $f(0.60,0.72,0.84,0.96,1.08$, and 1.20$)$ and $\alpha(0.0,0.2,0.4$, $0.6,0.8$, and 1.0). In order to check the robustness of the seismic response reduction performance under different ground motions, the MFVCS model with each parameter set was analyzed under 22 remote ground motions, which are recommended by FEMA695 [34]. Besides, the FE model of traditional megaframe shown in Figure 2 was also analyzed under those ground motions as the counterpart. Hence, the FE analysis with a total of 814 working conditions (36 MFVCS and 1 traditional megaframe counterpart under 22 ground motions) was conducted in the first stage.

The performance of the seismic response reduction was represented by the root-mean-square ratio (RMSR) of the top displacement. Optimized $f$ and $\alpha$ were obtained through comparing the RMSR of different working conditions. The equation for calculating RMSR is the following:

$$
\mathrm{RMSR}=\frac{\mathrm{RMS}_{\mathrm{VCS}}}{\mathrm{RMS}_{\mathrm{TMF}}}=\frac{\sqrt{(1 / N) \sum_{i=1}^{N} X_{i}^{2}}}{\sqrt{(1 / n) \sum_{i=1}^{n} x_{i}^{2}}},
$$

where $\mathrm{RMS}_{\mathrm{VCS}}$ and RMS $\mathrm{TMF}_{\mathrm{TMF}}$ are the root mean square of the top displacement of the MFVCS and traditional megaframe, respectively; $X_{i}$ and $x_{i}$ are the top displacement at time $i$ of the MFVCS and traditional megaframe, respectively; $N$ and $n$ are the number of the time step for the MFVCS and traditional megaframe, respectively.

In the second stage of the parametric analysis, the seismic response reduction of the MFVCS under rare earthquake $(\mathrm{PGA}=220 \mathrm{gal})$ was studied. Here, the optimized $f$ and $\alpha$ were adopted for the MFVCS. Both the MFVCS and 


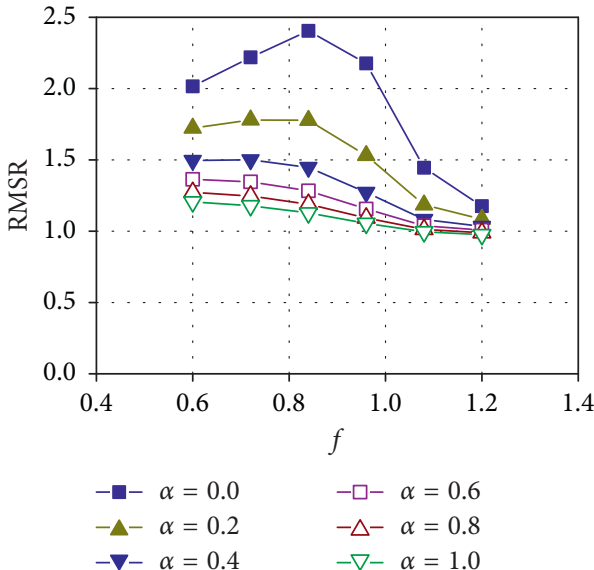

(a)

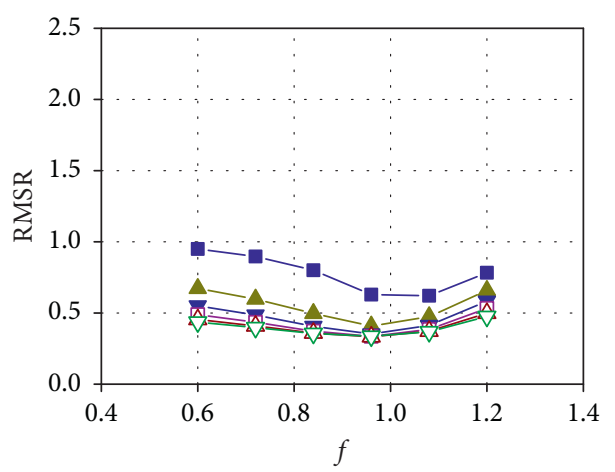

$-\square-\alpha=0.0$

$-\boldsymbol{\Delta}-\alpha=0.2$

$-\nabla-\alpha=0.4$

$-\square-\alpha=0.6$

$-\triangle-\alpha=0.8$

$-\nabla-\alpha=1.0$

(c)

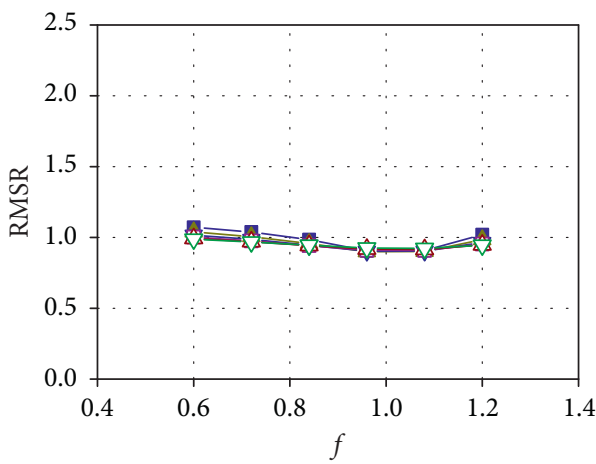

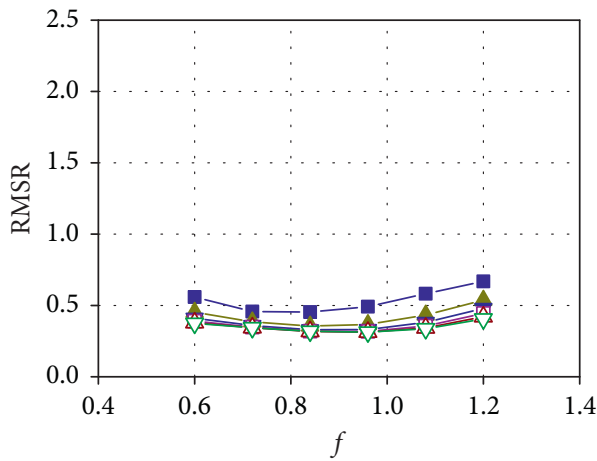

$$
\begin{array}{ll}
-\square-\alpha=0.0 & -\square-\alpha=0.6 \\
-\Delta-\alpha=0.2 & -\triangle-\alpha=0.8 \\
-\nabla-\alpha=0.4 & -\nabla-\alpha=1.0
\end{array}
$$

(b)

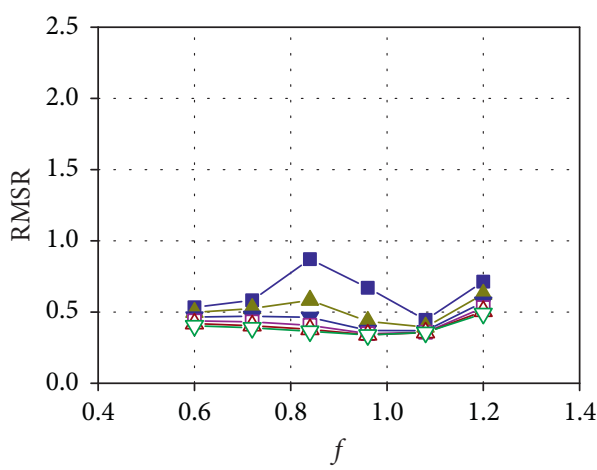

$$
\begin{array}{ll}
-\square=0.0 & -\square-\alpha=0.6 \\
-\Delta-\alpha=0.2 & -\triangle-\alpha=0.8
\end{array}
$$

(d)

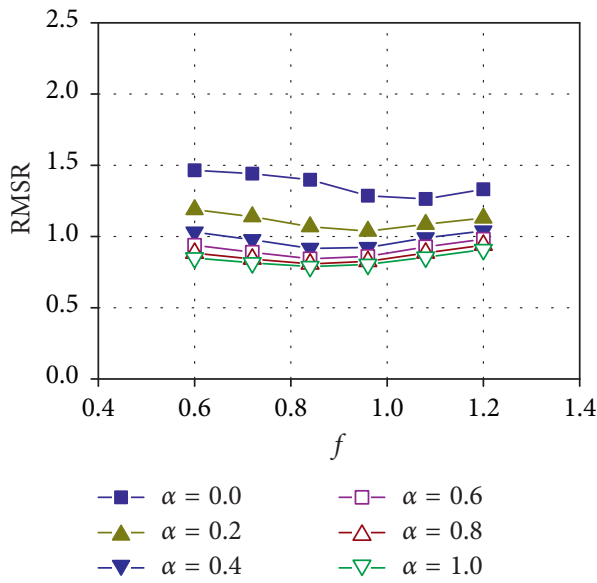

(f)

Figure 7: Continued. 

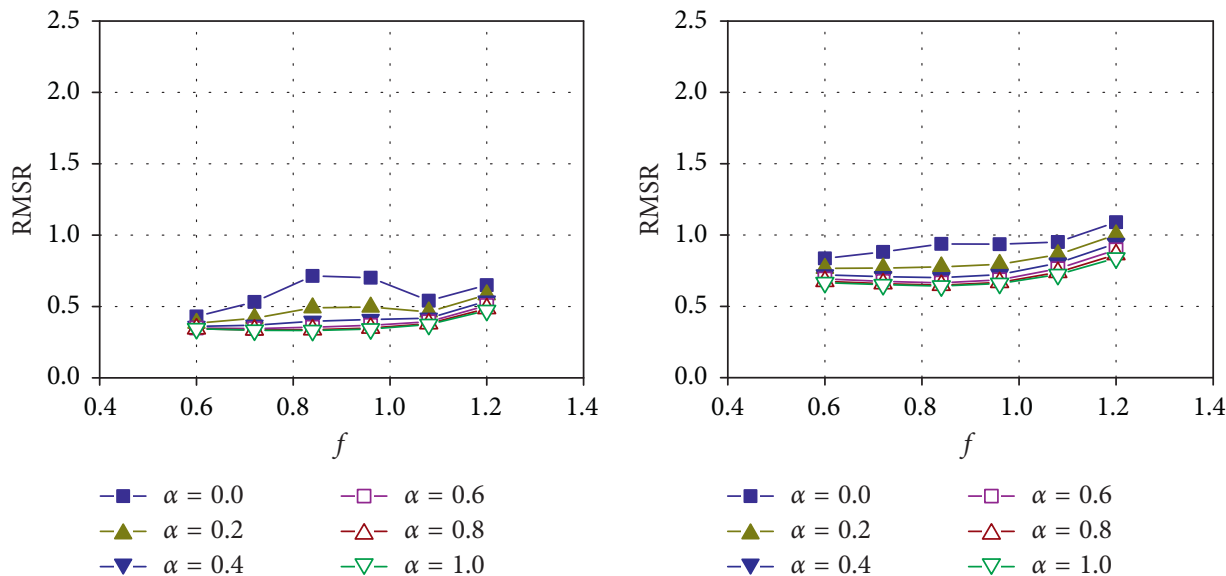

(g)

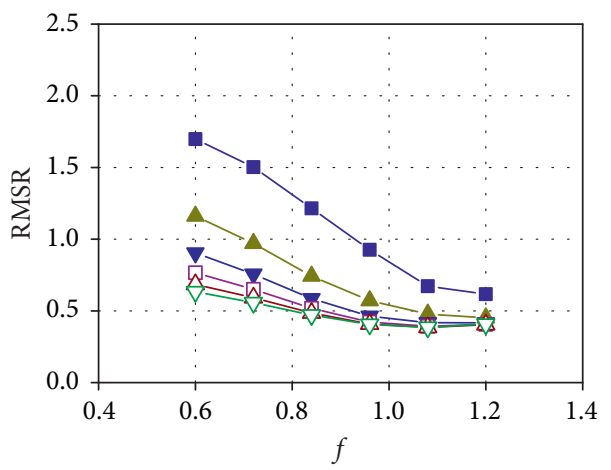

(h)

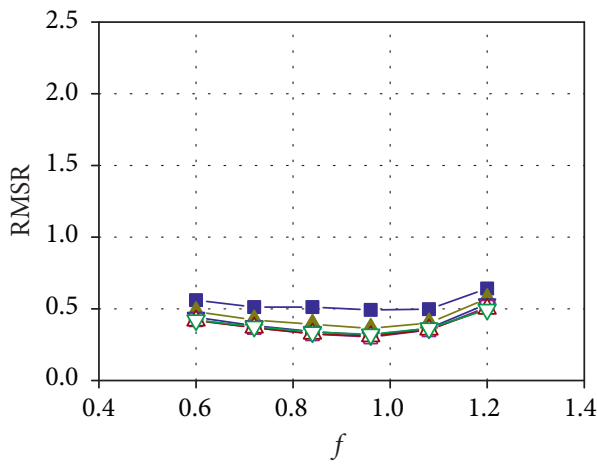

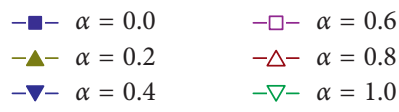

(i)

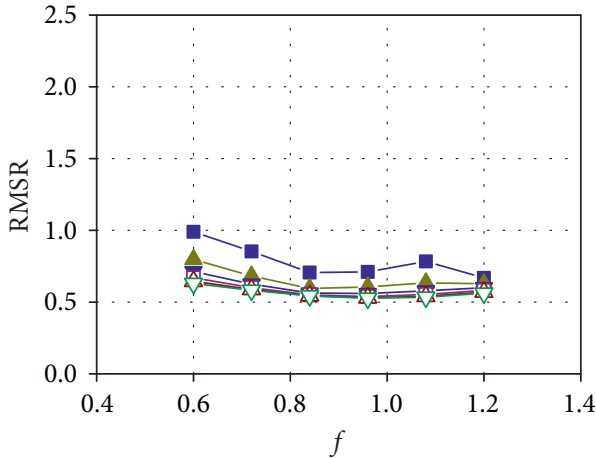

$-\square-\alpha=0.0$

$-\boldsymbol{-}-\alpha=0.2$

$-\boldsymbol{\nabla}-\alpha=0.4$

$-\square-\alpha=0.6$

$-\triangle-\alpha=0.8$

$-\nabla-\alpha=1.0$

(k)

$$
\begin{array}{ll}
-\square=0.0 & -\square-\alpha=0.6 \\
-\Delta-\alpha=0.2 & -\triangle-\alpha=0.8
\end{array}
$$

(j)

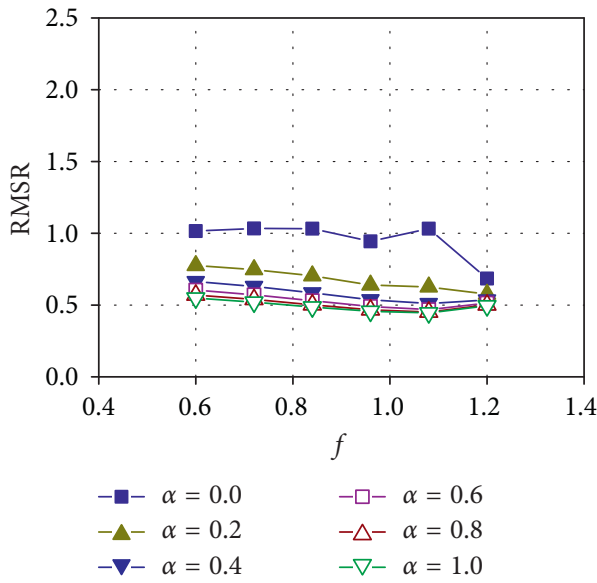

(1)

Figure 7: Continued. 


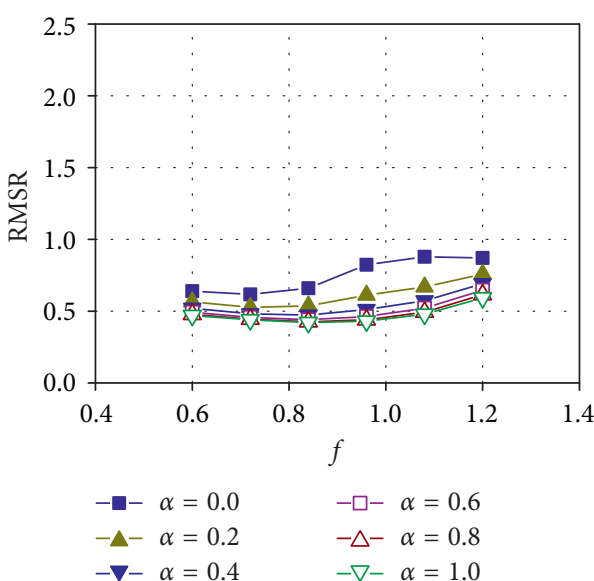

(m)

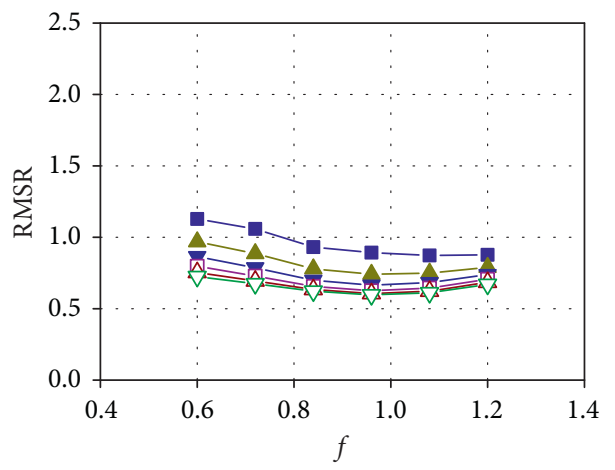

$-\square-\alpha=0.0$

$-\boldsymbol{\Delta}-\alpha=0.2$

$-\square-\alpha=0.6$

$-\triangle-\alpha=0.8$

$-\nabla-\alpha=1.0$

(o)

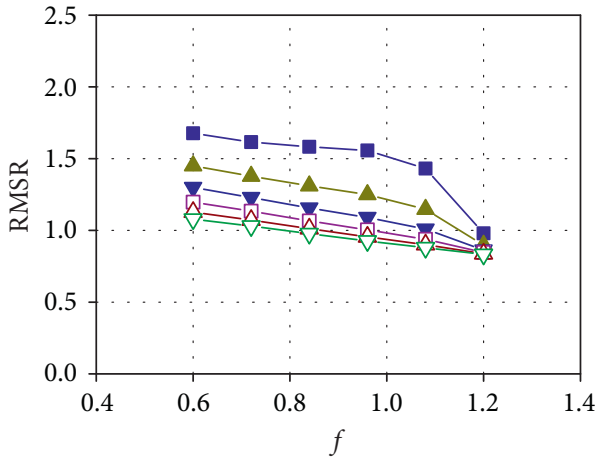

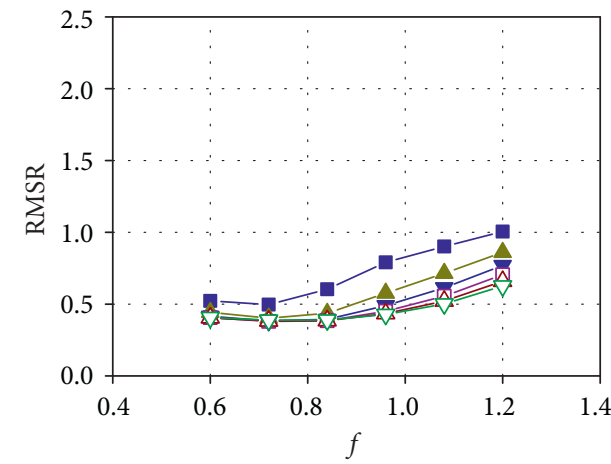

$$
\begin{array}{ll}
-\square=0.0 & -\square-\alpha=0.6 \\
-\triangle-\alpha=0.2 & -\triangle-\alpha=0.8 \\
-\nabla-\alpha=0.4 & -\nabla-\alpha=1.0
\end{array}
$$

(n)

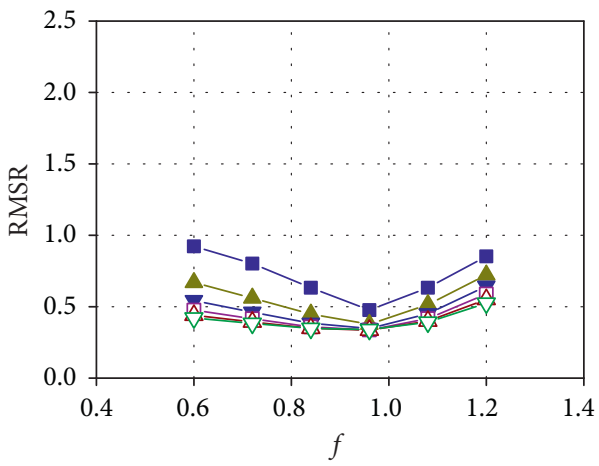

$-\square=0.0$
$-\Delta-\alpha=0.2$
$-\nabla-\alpha=0.4$

$-\square-\alpha=0.6$

$-\triangle-\alpha=0.8$

(p)

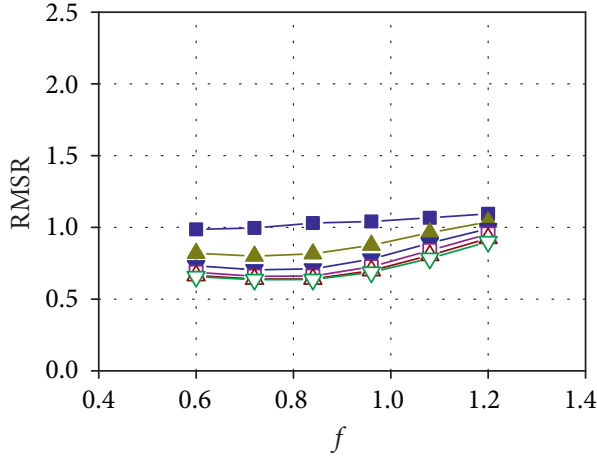

$$
\begin{array}{ll}
-\square=0.0 & -\square-\alpha=0.6 \\
-\Delta-\alpha=0.2 & -\triangle-\alpha=0.8 \\
-\nabla-\alpha=0.4 & -\nabla-\alpha=1.0
\end{array}
$$

(r)

Figure 7: Continued. 


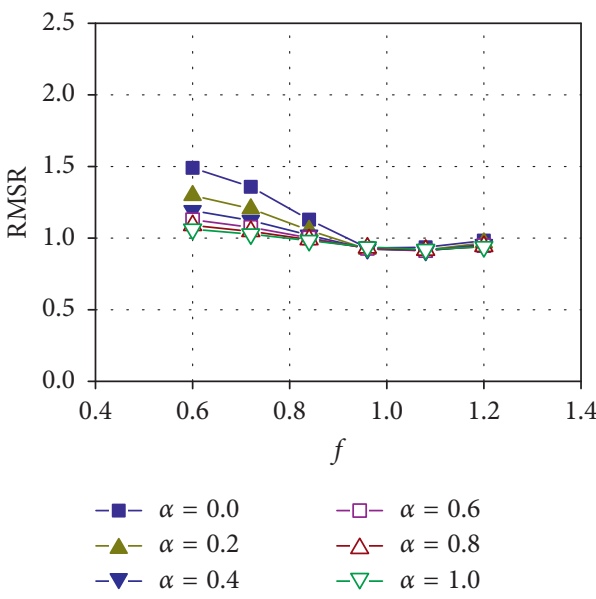

(s)

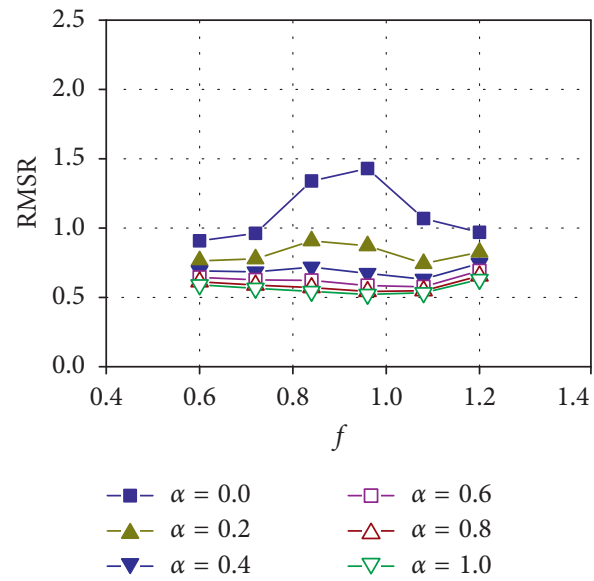

(u)

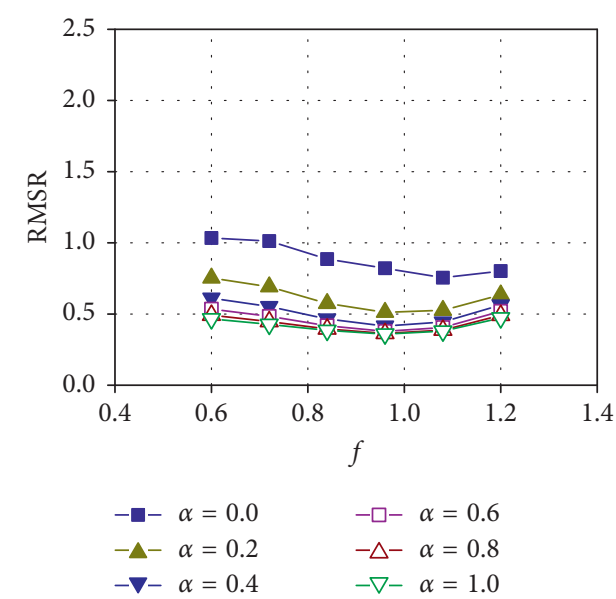

(t)

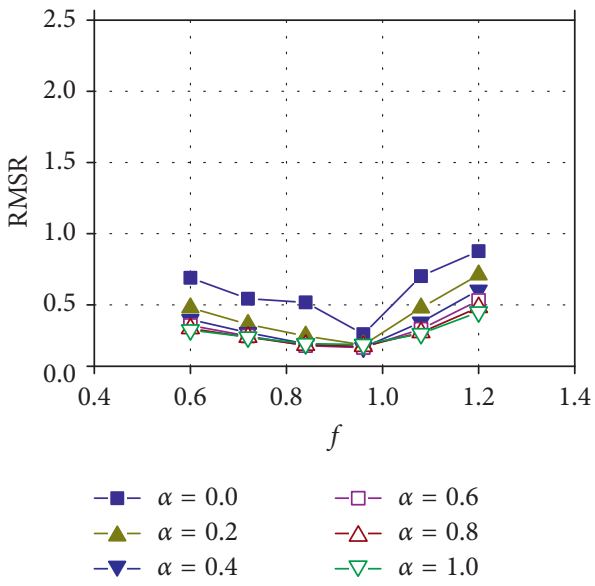

(v)

FIgURE 7: Relationships between RMSR, $f$, and $\alpha$ under different ground motions. (a) Northridge (NORTHR/MUL279), (b) Düzce Turkey (DUZCE/BOL090), (c) Hector mine (HECTOR/HEC090), (d) Imperial Valley (IMPVALL/H-DLT352), (e) Kobe (KOBE/SHI090), (f) Kocaeli Turkey (KOCAELI/DZC270), (g) Landers (LANDERS/YER360), (h) Loma Prieta (LOMAP/CAP090), (i) Manjil Iran (MANJIL/ABBAR-T), (j) Superstition Hills (SUPERST/B-POE360), (k) Cape Mendocino (CAPEMEND/RIO360), (l) Chi-Chi (CHICHI/TCU045-N), (m) San Fernando (SFERN/PEL180), (n) Friuli Italy (FRIULI/A-TMZ270), (o) Northridge (NORTHR/LOS270), (p) Imperial Valley (IMPVALL/H-E11230), (q) Kobe (KOBE/NIS090), (r) Kocaeli Turkey (KOCAELI/ARC090), (s) Landers (LANDERS/CLW-TR), (t) Loma Prieta (LOMAP/G03090), (u) Superstition Hills (SUPERST/B-ICC090), and (v) Chi-Chi (CHICHI/CHY101-N).

traditional megaframe were analyzed under those 22 ground motions mentioned above. In summary, a FE analysis with a total of 44 working conditions was conducted in this stage.

\subsection{Analysis Results and Discussion}

4.2.1. Seismic Response Reduction of MFVCS under Frequent Earthquake. The relationships between RMSR and $f$ of the MFVCS under different $\alpha$ values and different ground motions are shown in Figure 7. 85.2\% of the RMSR values listed in the figure were below 1.0 , and $33.6 \%$ of them were even lower than 0.5 . Besides, the RMSR remained almost constant when $\alpha \geq 0.4$. The average RMSR obtained in the first stage parametric analysis was 0.692 . Those observations indicated that compared with the traditional megaframe the proposed MFVCS could provide considerable seismic response reduction under frequent earthquake and had a strong robustness of performance when the ground motion, $f$, and $\alpha$ were considered as the uncertainties.

Figure 8 presents the typical time-history responses of top displacement between the MFVCS and traditional megaframe. The MFVCS with $f=0.96$ and $\alpha=1.0$ was adopted for the figure. From Figure 8, the MFVCS and traditional megaframe had the same behavior during the initial $9 \mathrm{~s}$ and $18 \mathrm{~s}$, respectively, as seen in Figures 8(a) and 8(b). After this initial period, the vibration of the MFVCS was sharply reduced. This observation indicated that the MFVCS needed time for the tuned mass to play its role and this feature was similar to that of the conventional TMD system [12]. The frequency response functions corresponding to the timehistory responses are also shown in Figure 8, in which the reduction on the magnitude of first-order frequency (i.e., the maximum value in the figure) could be observed. 


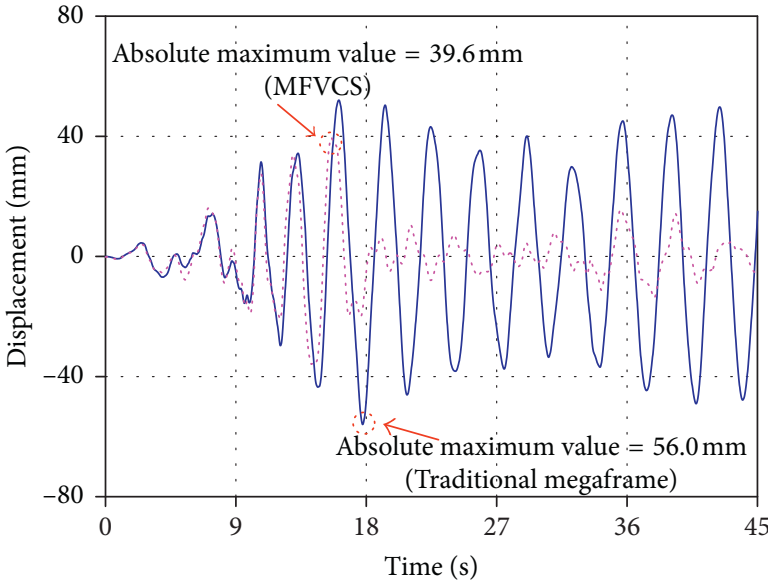

MFVCS

— Traditional megaframe

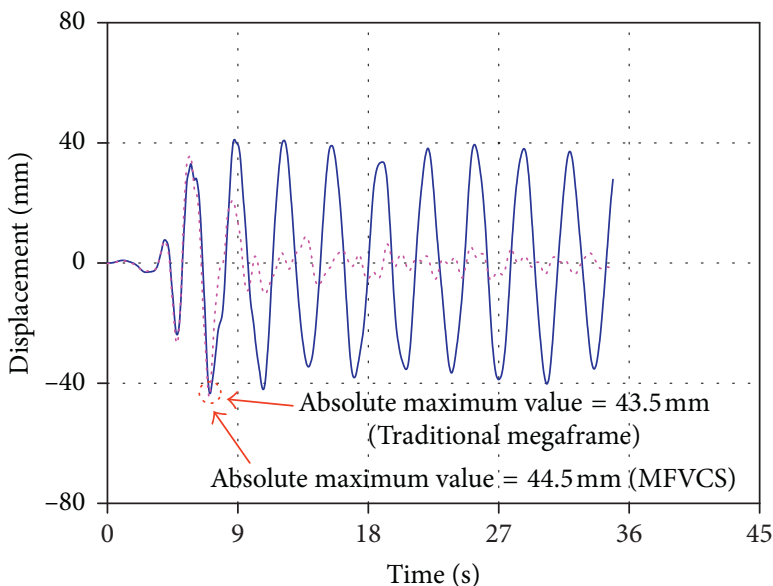

MFVCS

_ Traditional megaframe

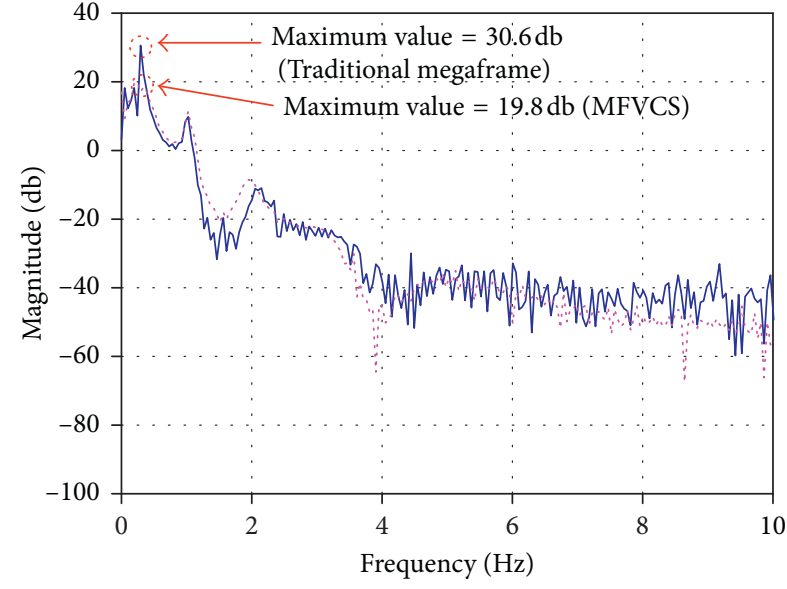

MFVCS

— Traditional megaframe

(a)

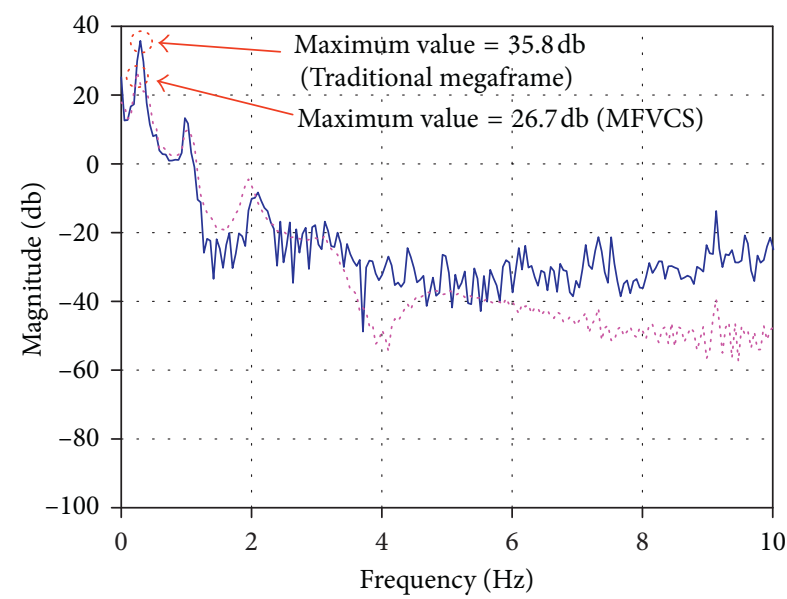

MFVCS

— Traditional megaframe

(b)

FIgURE 8: Comparison on the time-history response and corresponding frequency response function between MFVCS and traditional megaframe under frequent earthquake. (a) Manjil Iran (MANJIL/ABBAR--T) and (b) Loma Prieta (LOMAP/G03090).

TABLE 2: Values of RMSR ave with different $f$ and $\alpha$.

\begin{tabular}{lccccccc}
\hline$\alpha$ & & & & RMSR $_{\text {ave }}$ & & \\
& $f=0.60$ & $f=0.72$ & $f=0.84$ & $f=0.96$ & $f=1.08$ & $f=1.20$ & Average \\
\hline 0.0 & 1.006 & 0.973 & 0.970 & 0.906 & 0.863 & 0.880 \\
0.2 & 0.825 & 0.774 & 0.731 & 0.687 & 0.698 & 0.774 \\
0.4 & 0.729 & 0.680 & 0.633 & 0.602 & 0.628 & 0.718 \\
0.6 & 0.675 & 0.631 & 0.588 & 0.565 & 0.593 & 0.682 & 0.665 \\
0.8 & 0.642 & 0.604 & 0.566 & 0.549 & 0.574 & 0.622 \\
1.0 & 0.623 & 0.589 & 0.557 & 0.543 & 0.565 & 0.641 \\
Average & 0.750 & 0.708 & 0.674 & 0.642 & 0.654 & 0.725 & 0.586 \\
\hline
\end{tabular}

In order to explain the relationship between RMSR, $f$, and $\alpha$, the average RMSR of the 22 ground motions (named as $\mathrm{RMSR}_{\mathrm{ave}}$ ) is summarized in Table 2 and Figure 9. From Figure 9(a), with the increase in $f$, the RMSR $R_{\text {ave }}$ showed a slight initial decrease, with a small increase afterwards. The lowest $\mathrm{RMSR}_{\text {ave }}$ occurred when $f=0.96$, with an average value of 0.642 . From Figure 9(b), when $\alpha$ was within a range of 0.0-0.4, a sharp decrease in $\mathrm{RMSR}_{\text {ave }}$ with increasing $\alpha$ could be observed. This decrease tendency was not obvious when $\alpha \geq 0$.4. The lowest RMSR $_{\text {ave }}$ occurred when $\alpha=1.0$ 


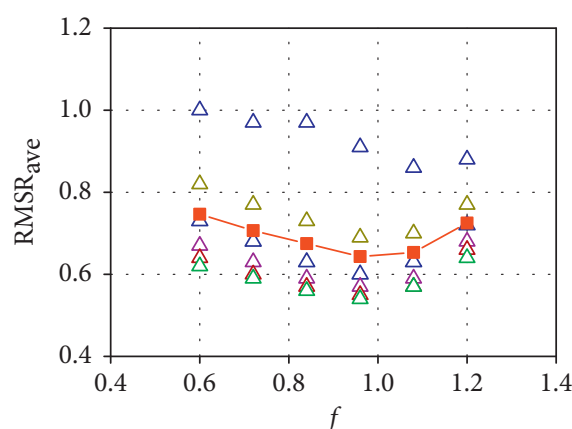

$\begin{array}{rlrl}\triangle \alpha & =0.0 & \triangle & \alpha=0.8 \\ \triangle \alpha & =0.2 & \triangle & \alpha=1.0 \\ \triangle \alpha & =0.4 & -\square-\text { Average } \\ \triangle \alpha=0.6 & & \end{array}$

(a)

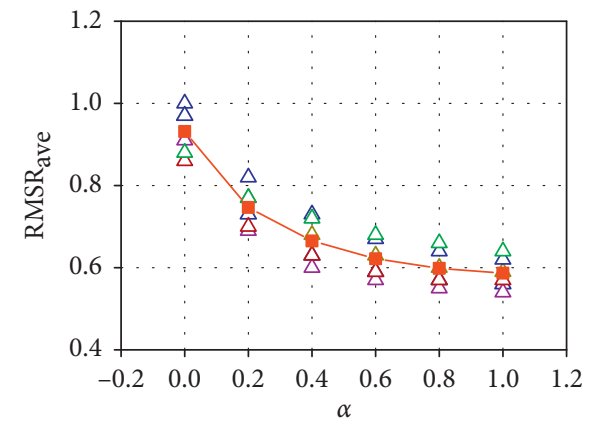

$\Delta f=0.60 \quad \Delta f=1.08$

$\triangle f=0.72$

$\triangle f=0.84$

$\Delta f=0.96$

$\Delta \quad f=1.20$
- Average

(b)

FIGURE 9: (a) Relationship between RMSR $_{\text {ave }}$ and $f$. (b) Relationship between RMSR ave and $\alpha$.

TABLE 3: RMSR of the MFVCS with $f=0.96$ and $\alpha=1.0$.

\begin{tabular}{|c|c|c|c|}
\hline \multirow{2}{*}{ Ground motion } & \multicolumn{2}{|c|}{ RMSR } & \multirow[b]{2}{*}{$r_{\text {case }}$} \\
\hline & Case 1 & Case 2 & \\
\hline $\begin{array}{l}\text { Northridge (NORTHR/MUL279) } \\
\text { (NOF) }\end{array}$ & 1.055 & 0.969 & 0.919 \\
\hline Düzce Turkey (DUZCE/BOL090) & 0.313 & 0.615 & 1.964 \\
\hline Hector mine (HECTOR/HEC090) & 0.336 & 0.653 & 1.941 \\
\hline Imperial Valley (IMPVALL/H-DLT352) & 0.339 & 0.845 & 2.494 \\
\hline Kobe (KOBE/SHI090) & 0.926 & 0.968 & 1.046 \\
\hline Kocaeli Turkey (KOCAELI/DZC270) & 0.804 & 0.755 & 0.939 \\
\hline Landers (LANDERS/YER360) & 0.342 & 0.607 & 1.773 \\
\hline Loma Prieta (LOMAP/CAP090) & 0.660 & 0.823 & 1.246 \\
\hline Manjil Iran (MANJIL/ABBAR-T) & 0.406 & 0.674 & 1.659 \\
\hline Superstition Hills (SUPERST/B-POE360) & 0.322 & 0.905 & 2.809 \\
\hline Cape Mendocino (CAPEMEND/RIO360) & 0.527 & 0.819 & 1.554 \\
\hline Chi-Chi (CHICHI/TCU045-N) & 0.456 & 0.999 & 2.190 \\
\hline San Fernando (SFERN/PEL180) & 0.430 & 0.548 & 1.273 \\
\hline Friuli Italy (FRIULI/A-TMZ270) & 0.428 & 0.347 & 0.811 \\
\hline Northridge (NORTHR/LOS270) & 0.597 & 0.658 & 1.102 \\
\hline Imperial Valley (IMPVALL/H-E11230) & 0.340 & 0.595 & 1.749 \\
\hline Kobe (KOBE/NIS090) & 0.926 & 0.694 & 0.750 \\
\hline Kocaeli Turkey (KOCAELI/ARC090) & 0.687 & 0.609 & 0.887 \\
\hline Landers (LANDERS/CLW-TR) & 0.937 & 0.876 & 0.935 \\
\hline Loma Prieta (LOMAP/G03090) & 0.359 & 0.501 & 1.394 \\
\hline Superstition Hills (SUPERST/B-ICC090) & 0.522 & 0.603 & 1.156 \\
\hline Chi-Chi (CHICHI/CHY101-N) & 0.221 & 0.634 & 2.863 \\
\hline Average $\left(\mathrm{RMSR}_{\mathrm{ave}}\right)$ & 0.543 & 0.714 & 1.315 \\
\hline
\end{tabular}

Note. Case 1 is the frequent earthquake; Case 2 is the rare earthquake; $r_{\text {case }}$ is the ratio of RMSR or RMSR ave between Case 2 and Case 1.

with an average value of 0.586 . Therefore, those optimized parameters $(f=0.96$ and $\alpha=1.0)$ were adopted for the analysis of the MFVCS under rare earthquake.

4.2.2. Seismic Response Reduction of MFVCS under Rare Earthquake. The RMSR of the MFVCS under rare earthquake was then analyzed and listed in Table 3. It could be seen that the values were all below 1.0 in those 22 ground motions. The obtained RMSR ave was 0.714 . These results indicated that the proposed MFVCS could still provide a good seismic response reduction under rare earthquake.

Table 3 also listed the RMSR comparison of the MFVCS under frequent and rare earthquakes. Generally, the RMSR under rare earthquake was larger, and the $\mathrm{RMSR}_{\text {ave }}$ under rare earthquake was 1.315 times as much as that under frequent earthquake which indicated that the seismic response reduction of the MFVCS was reduced under this condition. This observation could also be derived through a comparison of time-history response of the top displacement between the MFVCS and 


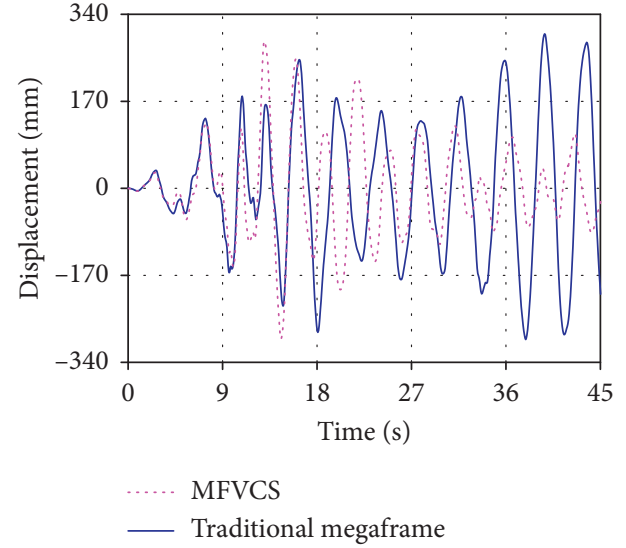

(a)

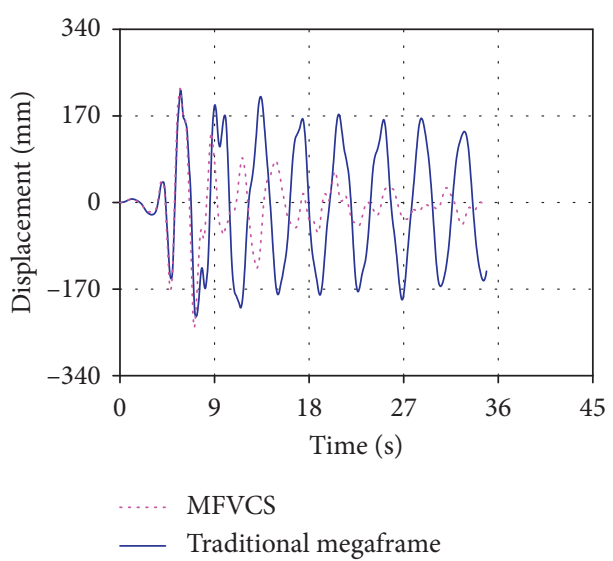

(b)

FIGURE 10: Comparison of time-history response of the top displacement between MFVCS and traditional megaframe under rare earthquake. (a) Manjil Iran (MANJIL/ABBAR--T) and (b) Loma Prieta (LOMAP/G03090).

the traditional megaframe (Figure 10). The reduced seismic response reduction performance mainly occurred because of the increase in $f$. According to the conducted shaking table test on the 1/25 scale megaframe model [2], owing to the damage occurred in the structure member during the test, its first mode natural frequency after a rare earthquake $(1.038 \mathrm{~Hz})$ could be 0.53 times as much as the original one $(1.961 \mathrm{~Hz})$. Similarly, for the MFVCS, $f_{\text {mega }}$ in (2) would be sharply decreased under a rare earthquake, which would cause $f$ larger than the optimized value and influence the seismic response reduction of MFVCS.

\section{Conclusions}

This study investigated the seismic response reduction of an unconventional tuned mass damper (TMD) system on a megaframe called megaframe with vibration control substructure (MFVCS). In this system, the top substructure was converted into a tuned mass by using lead-rubber bearings and viscous dampers to connect it with the megabeam and megacolumn, respectively. To this end, a finite element (FE) model was developed, and its accuracy was calibrated by the conducted shaking table test. The validated model was employed in a parametric analysis to study the effect of two key parameters (i.e., the tuning frequency and damping provided by lead-rubber bearings and viscous dampers) on the seismic response reduction under frequent earthquake (i.e., probability of exceedance of $63 \%$ in 50 years). The model with each parameter set was analyzed under 22 remote ground motions. The optimized values of the two parameters were obtained by comparing the rootmean-square ratio (RMSR) of the top displacement, and they were adopted for investigating the seismic response reduction under rare earthquake (i.e., probability of exceedance of $2 \%$ in 50 years). Based on the obtained results, the following conclusions are drawn:

(1) The proposed FE model was capable of predicting the dynamic behavior of the megaframe structures.
Based on the validated model, parametric analysis under frequent earthquake (i.e., peak ground acceleration was $35 \mathrm{gal}$ ) showed an average RMSR of 0.692 , in which $85.2 \%$ of the obtained RMSR values were below 1.0 and $33.6 \%$ of them were even lower than 0.5 , indicating a considerable seismic response reduction and a strong robustness (when the ground motion, tuning frequency, and investigated damping were considered as the uncertainties).

(2) The optimized values of the frequency ratio (ratio of tuning frequency to the megaframe's natural frequency) and damping scale factor (ratio between the investigated damping and a standard value) were 0.96 and 1.0, respectively, based on the analysis result of the MFVCS under frequent earthquake.

(3) The proposed MFVCS could still provide seismic response reduction under rare earthquake (i.e., peak ground acceleration was $220 \mathrm{gal}$ ) through adopting the optimized frequency ratio (0.96) and damping scale factor (1.0). However, its performance was reduced owing to the change in the structure natural frequency induced by the damage of structure member.

\section{Data Availability}

The authors declare that all data supporting the findings of this study are available within the article.

\section{Conflicts of Interest}

The authors declare that there are no conflicts of interest regarding the publication of this paper.

\section{Acknowledgments}

This research was financially supported by the National Natural Science Foundation of China (Grant nos. 51408409 
and 51378167) and State Key Laboratory of Subtropical Building Science (Grant no. 2015ZA04)

\section{References}

[1] M. M. Ali and K. S. Moon, "Structural developments in tall buildings: current trends and future prospects," Architectural Science Review, vol. 50, no. 3, pp. 205-223, 2007.

[2] Q. Jiang, X. Lu, H. Guan, and X. Ye, "Shaking table model test and $\mathrm{FE}$ analysis of a reinforced concrete mega-frame structure with tuned mass dampers," The Structural Design of Tall and Special Buildings, vol. 23, no. 18, pp. 1426-1442, 2014.

[3] H. Fan, Q. S. Li, A. Y. Tuan, and L. Xu, "Seismic analysis of the world's tallest building," Journal of Constructional Steel Research, vol. 65, no. 5, pp. 1206-1215, 2009.

[4] X. Lu, X. Lu, W. Zhang, and L. Ye, "Collapse simulation of a super high-rise building subjected to extremely strong earthquakes," Science China Technological Sciences, vol. 54, no. 10, pp. 2549-2560, 2011.

[5] H. Frahm, "Device for damping of bodies," US Patent No: 989-911.

[6] J. Ormondroyd and J. P. Den Hartog, "The theory of dynamic vibration absorber," Transactions of the American Society of Mechanical Engineers, vol. 50, pp. 9-22, 1928.

[7] M. G. Soto and H. Adeli, "Tuned mass dampers," Archives of Computational Methods in Engineering, vol. 20, pp. 419-431, 2013.

[8] J. Connor and S. Laflamme, Tuned Mass Damper Systems, Structural Motion Engineering, Springer, Berlin, Germany, 2014.

[9] S. Elias and V. Matsagar, "Research developments in vibration control of structures using passive tuned mass dampers," Annual Reviews in Control, vol. 44, pp. 129-156, 2017.

[10] S. Elias and V. Matsagar, "Wind response control of tall buildings with a tuned mass damper," Journal of Building Engineering, vol. 15, pp. 51-60, 2018.

[11] A. Y. Tuan and G. Q. Shang, "Vibration control in a 101-storey building using a tuned mass damper," Journal of Applied Science and Engineering, vol. 17, pp. 141-156, 2014.

[12] J. R. Sladek and R. E. Klingner, "Effect of tuned-mass dampers on seismic response," Journal of Structural Engineering, vol. 109, no. 8, pp. 2004-2009, 1983.

[13] R. Rana and T. T. Soong, "Parametric study and simplified design of tuned mass dampers," Engineering Structures, vol. 20, no. 3, pp. 193-204, 1998.

[14] M. De Angelis, S. Perno, and A. Reggio, "Dynamic response and optimal design of structures with large mass ratio TMD," Earthquake Engineering \& Structural Dynamics, vol. 41, no. 1, pp. 41-60, 2012.

[15] M. Q. Feng and A. Mita, "Vibration control of tall buildings using mega subconfiguration," Journal of Engineering $\mathrm{Me}$ chanics, vol. 121, no. 10, pp. 1082-1088, 1995.

[16] M. Q. Feng and W. Chai, "Design of a mega-sub-controlled building system under stochastic wind loads," Probabilistic Engineering Mechanics, vol. 12, no. 3, pp. 149-162, 1997.

[17] W. Chai and M. Q. Feng, "Vibration control of super tall buildings subjected to wind loads," International Journal of Non-Linear Mechanics, vol. 32, no. 4, pp. 657-668, 1997.

[18] W. Chai and M. Q. Feng, "Seismic performance of mega-sub controlled buildings," in Proceedings of 11th World Conference on Earthquake Engineering, pp. 23-28, Acapulco, Mexico, June 1996.

[19] Z. Lan, X. Wang, H. Dai, and S. Liang, "Multifunctional vibration-absorption RC megaframe structures and their seismic responses," Earthquake Engineering \& Structural Dynamics, vol. 29, no. 8, pp. 1239-1248, 2000.

[20] X. A. Zhang, J. Zhang, D. Wang, and J. Jiang, "Controlling characteristics of passive mega-subcontrolled frame subjected to random wind loads," Journal of Engineering Mechanics, vol. 131, no. 10, pp. 1046-1055, 2005.

[21] X. A. Zhang, D. Wang, and J. Jiang, "The controlling mechanism and the controlling effectiveness of passive mega-sub-controlled frame subjected to random wind loads," Journal of Sound and Vibration, vol. 283, no. 3-5, pp. 543-560, 2005.

[22] T. Li, X. A. Zhang, and Q. Wang, "Control characteristics of mega-sub controlled structure system with friction damper under rare earthquake," in Proceedings of International Multi Conference of Engineers and Computer Scientists, pp. 16-18, Hong Kong, March 2011.

[23] Y. Lian, X. Zhang, and C. Sheldon, "Damping characteristics of friction damped braced frame and its effectiveness in the mega-sub controlled structure system," Earthquake Engineering and Engineering Vibration, vol. 6, no. 2, pp. 171-181, 2007.

[24] X. Li, P. Tan, X. Li, and A. Liu, "Mechanism analysis and parameter optimization of mega-sub-isolation system," Shock and Vibration, vol. 2016, Article ID 2605839, 12 pages, 2016.

[25] Z. Lan, Y. Tian, L. Fang, S. Liang, and X. Wang, "An experimental study on seismic responses of multifunctional vibration-absorption reinforced concrete megaframe structures," Earthquake Engineering \& Structural Dynamics, vol. 33, no. 1, pp. 1-14, 2004.

[26] X. X. Li, P. Tan, L. K. Liu, Y. Zhang, F. L. Zhou, and X. J. Li, "Comparative analysis of mega-sub control system by shaking table test and finite element modeling," Engineering $\mathrm{Me}$ chanics, vol. 33, pp. 76-84, 2016, in Chinese.

[27] D. Gill, S. Elias, A. Steinbrecher, C. Schroder, and V. Matsagar, "Robustness of multi-mode control using tuned mass dampers for seismically excited structures," Bulletin of Earthquake Engineering, vol. 15, no. 12, pp. 5579-5603, 2017.

[28] ACI 318M-05, Building Code Requirements for Structural Concrete and Commentary, American Concrete Institute, Farmington Hills, MI, USA, 2005.

[29] Eurocode 8, Design Provisions for Earthquake Resistance of Structures. Part 1: General Rules, Seismic Actions and Rules for Buildings, BS EN 1998-1, Brussels, Belgium, 2004.

[30] V. A. Matsagar and R. S. Jangid, "Influence of isolator characteristics on the response of base-isolated structures," Engineering Structures, vol. 26, no. 12, pp. 1735-1749, 2004.

[31] GB50011-2010, Chinese Code for Seismic Design of Buildings, Architecture \& Building Press, Beijing, China, 2010, in Chinese.

[32] JGJ3-2002, Technical Specification for Concrete Structures of Tall Building, Architecture \& Building Press, Beijing, China, 2002, in Chinese.

[33] Q. Jiang, X. Z. Lu, X. Chong, X. G. Ye, and J. Q. Huang, "Damping effect analysis of mega-frame structures with a vibration absorption substructure," Engineering Mechanics, vol. 32, pp. 39-44, 2015, in Chinese.

[34] P. 695 FEMA, Quantification of Building Seismic Performance Factors, Federal Emergency Management Agency, Washington, DC, USA, 2009. 


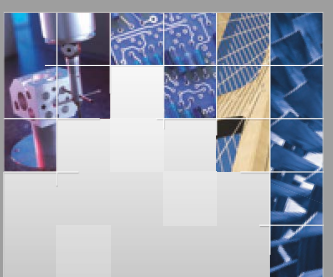

\section{Enfincering}
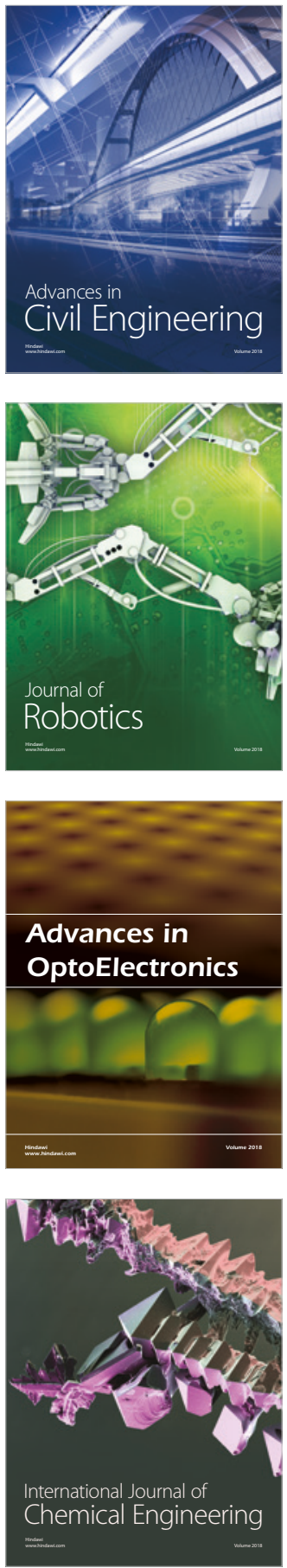

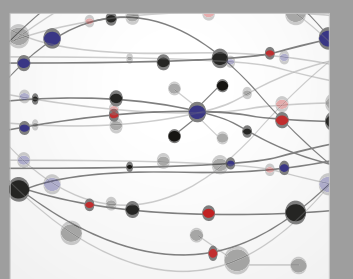

\section{Rotating \\ Machinery}

The Scientific World Journal

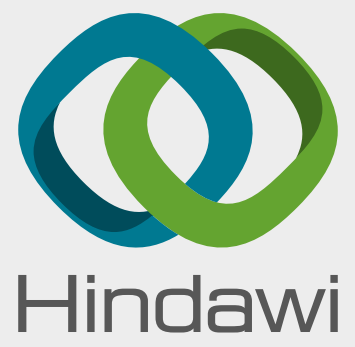

Submit your manuscripts at

www.hindawi.com
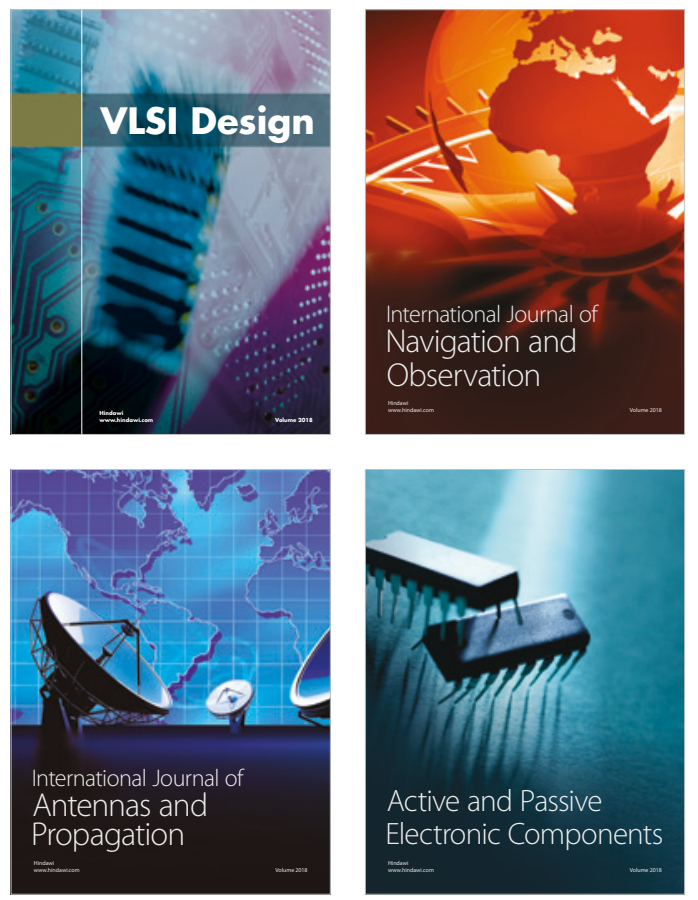
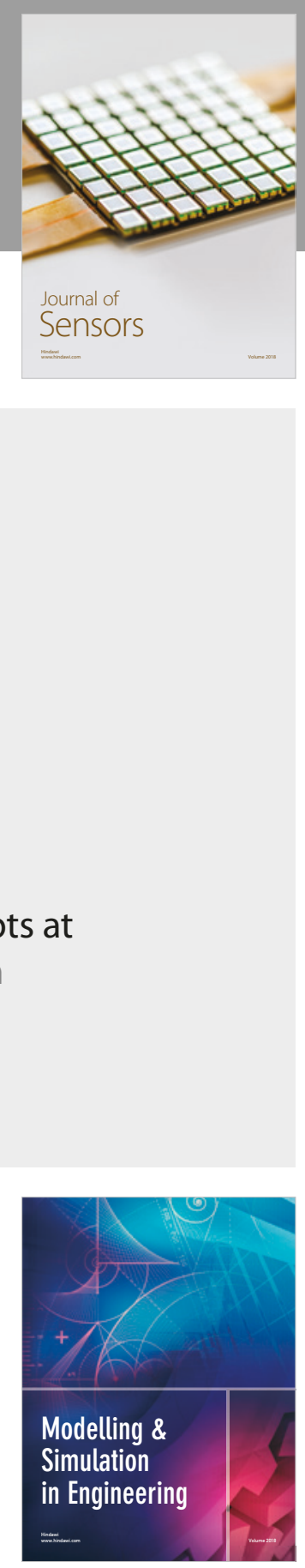

\section{Advances \\ Multimedia}
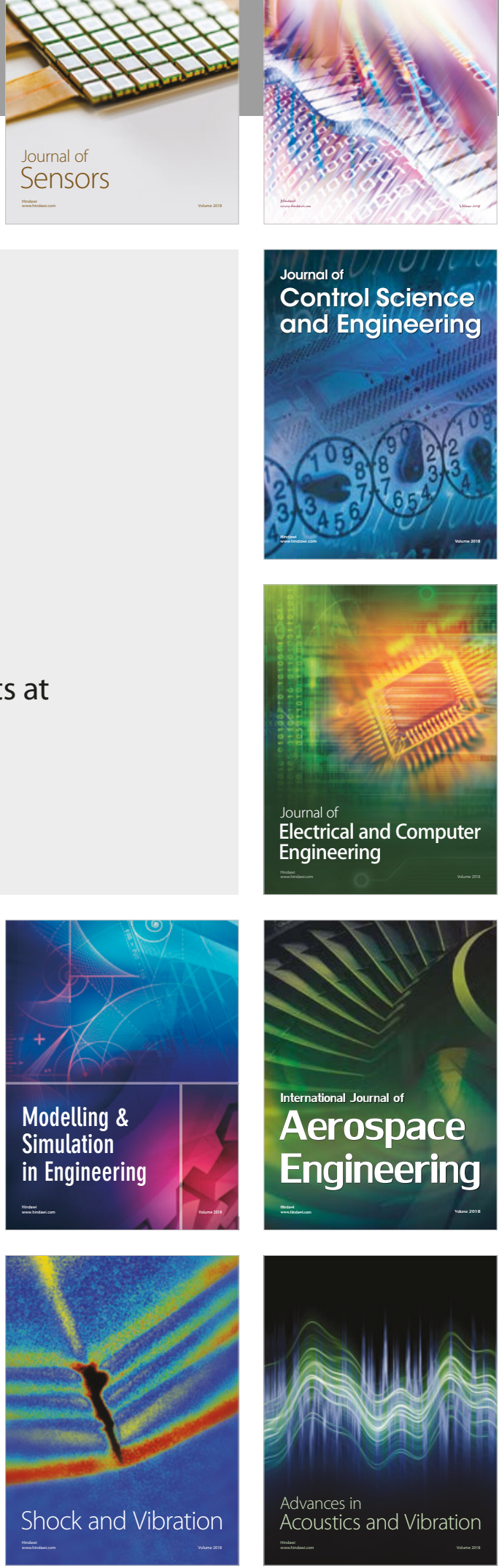